\title{
Effects of chlorinated aliphatic hydrocarbons on the fidelity of cell division in human CYP2E1 expressing cells
}

\author{
Adele Kim ${ }^{1,2,3}$, Elizabeth M Parry ${ }^{2}$ and \\ James M Parry ${ }^{2}$ \\ ${ }^{1}$ Samsung Medical Center, 50 ILwon-dong, Kangnam-ku, \\ Seoul 135-710, Korea \\ ${ }^{2}$ Centre for Molecular Genetics and Toxicology, School of Biological \\ Sciences, University of Wales Swansea \\ ${ }^{3}$ Corresponding author: Tel, +82-2-880-5207; \\ Fax, +82-2-873-7482; E-mail, aquarius70@hanmail.net
}

Accepted 15 March 2002

Abbreviations: D/L/B, dislocated/lagging/bridging chromosomes; $\mathrm{CC}$, chromosome cluster; CM, chromatin mass; CS, chromosome scatters; NORM, normal mitosis; MULTI, multi-polar spindle; SC, scattered chromatin; TCE, trichloroethylene

\begin{abstract}
Chlorinated organic chemicals are widely used in industry and are present in the environment. Five chlorinated aliphatic hydrocarbons, namely 1-2dichloroethane, 1,1,2-trichloroethane, trichloroethylene, 2,3-dichlorobutane and 1-chlorohexane were investigated to determine their influence upon the fidelity of cell division in cultured mammalian cells. In order to determine the influence of these chemical compounds upon the fidelity of cell division, a technique known as differential staining of chromosomes and spindle was performed with one genetically engineered cell line and its parental cell line. The genetically engineered cell line used in this study expressed a human P450 enzyme, CYP2E1. Four chemicals, 1-2-dichloroethane, trichloroethylene, 23-dichlorobutane and 1-chlorohexane required metabolic bioactivations in order to induce spindle damage in cultured mammalian cells whereas 1,1,2trichloroethane was a direct-acting spindle poison.
\end{abstract}

Keywords: Chromosome aberrations, cytochrome P450 CYP2E1, hydrocarbons, chlorinated, mitotic spindle apparatus

\section{Introduction}

The maintenance of the chromosome karyotype of an eukaryotic organism is dependent upon the fidelity of chromosome replication and the segregation of chromosomes during both mitotic and meiotic cell division. Both of these divisions depend upon the synthesis and functioning of the proteins of the nuclear spindle and the attachment and movement of chromosomes on the spindle apparatus.

In order to study the effects of chlorinated aliphatic hydrocarbons upon the fidelity of chromosome replication and the segregation of chromosomes during mitosis, a technique known as differential staining was developed (Wissinger et al., 1981) and this technique was used in this study. This technique involves a fixation procedure to maintain the integrity of the spindle apparatus and differential staining using Brilliant Blue $R$ (to visualize spindle proteins) and Safronin O (to visualize the chromosomes).

Chlorinated aliphatic hydrocarbons are a group of chemicals widely used and processed in industry. Some of these chlorinated aliphatic hydrocarbons tested are already known to be carcinogens and/or mutagens in some mammals. These chemical compounds are often found in drinking water (Eurocop-Cost, 1976) as well as in air (Fdujii, 1977), therefore investigating the genotoxicity of these chemical compounds are thought to be imperative.

Most of the chemicals inducing genetic damage require metabolic biotransformation to produce their ultimate metabolites. These demands are fulfilled with animals, however using animals for investigating genetic damage is complicated due to their complexity of the xenobioticmetabolizing enzyme system. In addition, animal experiments are time consuming, and expensive. Animal experiments can also raise ethical problems. For these reasons, eukaryotic cells like the V79 Chinese hamster cells, lacking the expression of cytochromes P-450 which is required for the metabolic biotransformation, have been genetically engineered to express one of the human cytochromes P-450 designated CYP2E1.

CYP2E1 is a single member of the CYP2E subfamily. It is present in humans, rats, rabbits, monkeys and mice. It is constitutively expressed in human liver (Yoo et al., 1988) but may be induced by the administration of ethanol and acetone (Koop and Tierney, 1990) or fasting and diabetes (Lieber,1988: Ronis et al., 1993).

Here, the parental and genetically engineered V79 Chinese hamster cell lines have been used to test five chlorinated aliphatic hydrocarbons upon the fidelity of cell division. 


\section{Materials and Methods}

\section{Cell lines}

Two cell lines were used in this study.

1) V79d-MZ: An immortalized Chinese hamster (Cricetelus griseus) lung cell line provided by the University of Mainz.

2) MB1: An immortalized Chinese hamster (Cricetelus griseus) lung cell line that has been genetically engineered to express cytochromes P450 (CYP2E1) and was provided by Martina Barrenscheen and the MB stands for Martina Barrenscheen.

\section{Cell culture}

The cells (V79d-MZ) were routinely maintained in Dulbecco's Modified Eagles medium (DMEM) supplemented with $10 \%$ fetal bovine serum with additional glucose (4.5 g/l, BDH), L-glutamine (584 mg/l), penicillin (50 IU/ $\mathrm{ml})$, streptomycin $(50 \mathrm{u} / \mathrm{ml})$ and $\mathrm{NaHCO}_{3}(3.7 \mathrm{G} / \mathrm{l}, \mathrm{BDH})$. MB1 cells were routinely maintained in the same medium with another supplement of G418 (geneticin sulphate) in order to select the cells with the plasmids expressing the P4502E1. They were grown as a monolayer and, once confluent, they were split using $0.25 \%$ trypsin to detach them. Incubation was at $37^{\circ} \mathrm{C}$ in a $95 \%$ air/ $\mathrm{CO}_{2}$ atmosphere.

The cell cycle time was estimated to be $12 \mathrm{~h}$ for the V79d-MZ and $16 \mathrm{~h}$ for the MB1 cells, using cell counts to measure doubling time.

\section{Mitotic profile and spindle studies}

A differential staining technique described by Wissinger et al. (1981) was used to simultaneously observe the chromosomes and spindle fibers at mitosis as described previously (Parry et al., 1982).

Slide cultures were set up by seeding $1 \mathrm{ml} / \mathrm{slide}$ of a $75000 \mathrm{cells} / \mathrm{ml}$ suspension onto sterile glass slides in square petri dishes. After $2 \mathrm{~h}$, to allow attachment, cells were kept in the appropriate medium for a night then the cells were treated with the test chemicals. For each cell line, the treatment time was 1.33 of cell cycle time.

After the chemical treatment, the cells were washed twice in Hank's Balanced Salt Solution (HBSS). The slides were then labeled in pencil and were fixed in 3:1 methanol: acetic acid. Fixative was made freshly before use and included $4 \mathrm{mM} \mathrm{MgCl} 2$ and $1.5 \mathrm{mM} \mathrm{CaCl}_{2}$. Cells were fixed at room temperature 3 times for 14 min each. Following over night air drying, the slides were placed in $5 \%$ perchloric acid solution at $4^{\circ} \mathrm{C}$ for $24 \mathrm{~h}$ to remove RNA. The slides were rinsed for $10 \mathrm{~min}$ in several changes of distilled water and air-dried before staining with a solution of $0.5 \%$ Brilliant blue R (Sigma Chemical Co.) and $0.5 \%$ Safranin O (Harleco Co.) in $15 \%$ acetic acid for $24 \mathrm{~h}$. The slides were washed in distilled water, air-dried, soaked briefly in xylene and then mounted with DPX (BDH Ltd.).

The slides were then coded and scored for mitotic index (1000 cells were counted/slide, 3 replicates/dose), and 100 dividing cells/slide (3 replicates/dose) were classified as normal (prophase, metaphase, anaphase and telophase) or aberrant. Chromosomes dislocation from the spindle, multi-polar spindles and anaphase bridges and lagging were also recorded. The aberrant stages lacked spindles and were classified into 4 groups: (1) Chromosome cluster, when the chromosomes were all lightly clustered centrally in the cell. (2) Scattered chromosomes, when the chromosomes lie scattered throughout the cell. (3) Chromatin mass, when there was a single mass of chromatin material. (4) Scattered chromatin, when more than one mass of chromatin was seen in the cell.

\section{Cytotoxicity Assay}

Normally cytotoxicity tests are carried out before commencing major assays in order to have an idea of dose range however in this research it was not essential since the chemicals have already been used for cytotoxicity and micronucleus assays (Doherty, 1996) the dose range used in this research was based on those previous assays.

\section{Handling of toxic substances}

Known toxic or potentially toxic compounds were handled with care. Disposable gloves and aprons were worn while working with such chemicals. All the work was performed with a safety cabinet with discarded equipments and chemicals disposed for incineration.

\section{Photography}

All the images were captured on a Perceptive Instruments Image Analysis System and prints were produced via a Tektronix Phaser Ilsdx colour printer.

\section{Results and Discussion}

Five chlorinated aliphatic hydrocarbons have been tested using the differential staining technique and each chemical compound showed distinct mitotic profiles for different cell lines. The mitotic profiles presented by each chemical compound are illustrated graphically in Figure 1 to Figure 5.

The mitotic profiles of both cell lines V79d-MZ and MB1 treated with five chlorinated aliphatic hydrocarbons were evaluated in this study. Although it is not shown here, mitotic index was also measured as done by Szende and co-workers (2000). The mitotic profiles of different cell lines treated with each chemical compound varied from one another and the results of each chemical compound will be described individually and 
1,2-dichloroethane (V79d-MZ)
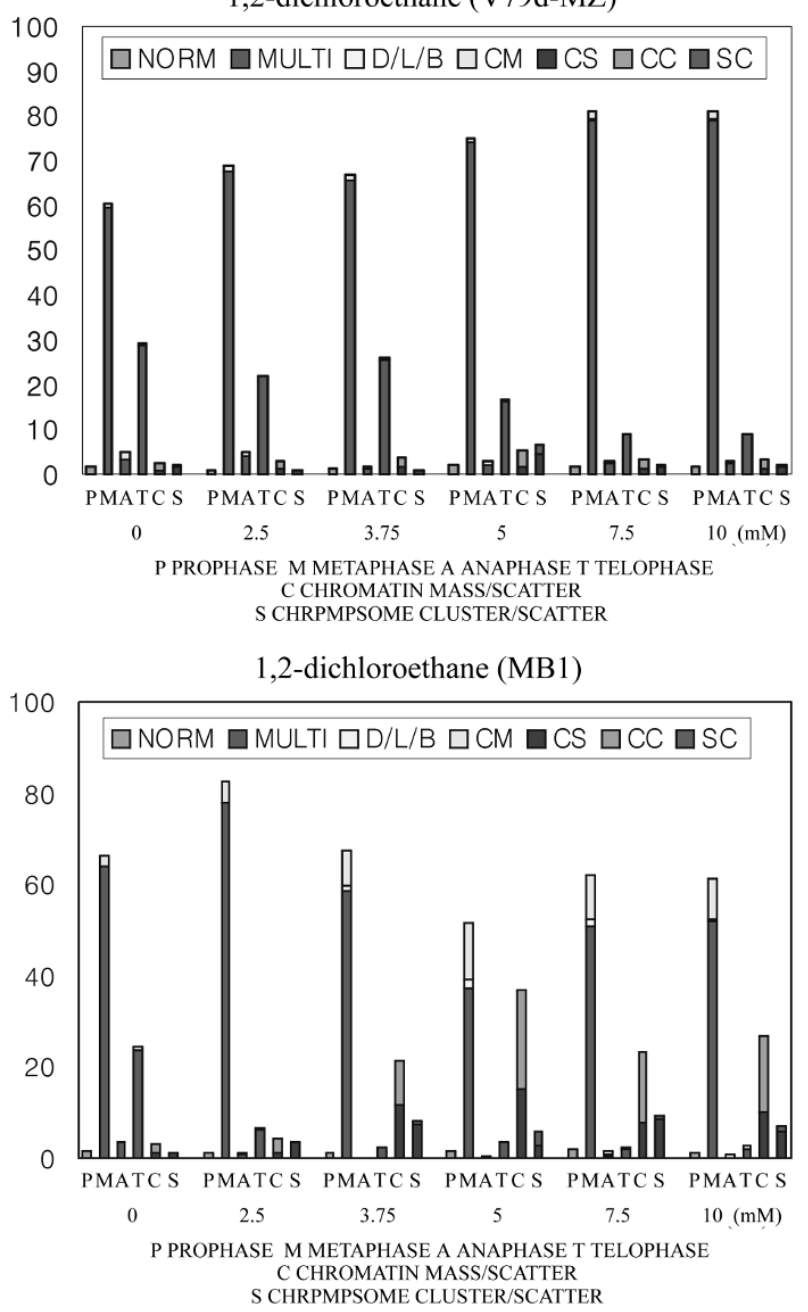

Figure 1. Mitotic profiles of $\mathrm{V} 79 \mathrm{~d}-\mathrm{MZ}(\mathrm{A})$ and $\mathrm{MB} 1(\mathrm{~B})$ treated with 1,2dichloroethane. Cells were treated for 16 and $22 \mathrm{~h}$, respectively with $1,2-$ dichloroethane before the cells were differentially stained to observe their mitotic profiles. Most cells were normal even at the highest dose of $10 \mathrm{mM}$ for V79d-MZ, whereas several aberrations were found in MB1.

the results will be discussed further by comparing them with other published data.

\section{1,2-dichloroethane}

This chemical compound, although both cell lines were treated up to $10 \mathrm{mM}$, did not show much adverse effect on the fidelity of cell division in V79d-MZ (Figure 1A) whereas the effect of the chemical is more prominent in the MB1 cell line. As the dose was elevated, number of mitotic cells with spindle aberrations increased but they were not dose-dependent (Figure 1B).

In the MB1 cell line, 1,2-dichloroethane induced multipolar spindles (Photo 2) and a large number of dislocated chromosomes as shown in Photo1, but both effects were not also dose-dependent (Figure 1B). Bridges were formed during anaphase in many cells (Photo 3 )
1

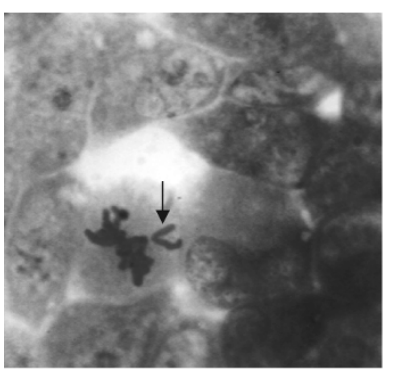

3

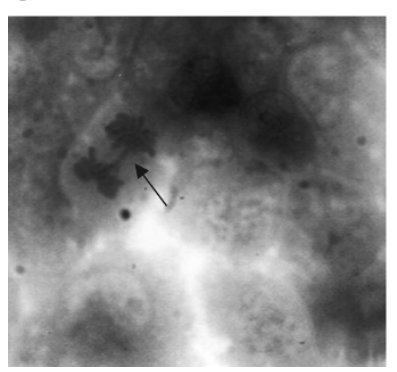

2

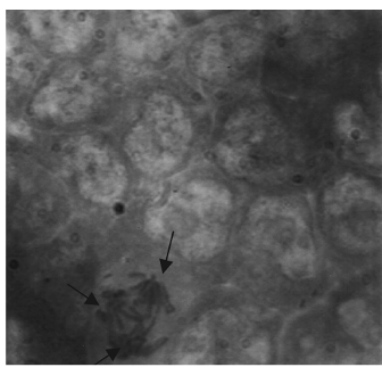

4

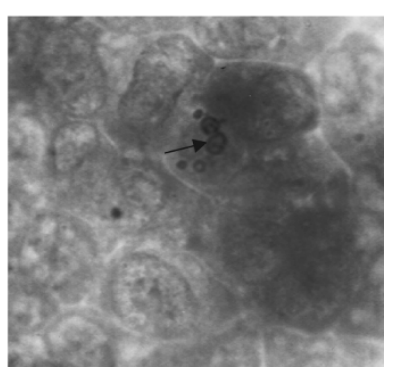

Photo 1. Dislocated chromosome. When cells are treated with a spindle poison, spindles get damaged and a dislocated chromosome is produced as shown here.

Photo 2. Multipolar spindle. If cells do not divide properly, spindles may become multipolar.

Photo 3. Bridge formation during anaphase. If a chemical compound used to treat cells is damaging the function or the structure of the kinetochore, a bridge may be formed, this is due to the slow movement of chromosome. Photo 4. Chromatin mass. If the cells are damaged irreversibly, chromatin mass is shown and this represent cell death.

and many cells with chromatin scatters (Photo 4) and chromatin mass were induced by this chemical compound in MB1 cell line (Figure 1B).

This chemical compound was not a spindle poison unless it was activated by CYP2E1 enzyme since a large number of aberrant cells were scored only in MB1 cell line.

1,2-dichloroethane required an activation of the enzyme CYP2E1 to induce a significant amount of spindle damage in Chinese hamster lung fibroblast cells but this does not seem to coincide with the results of micronucleus assay performed by Doherty and co-workers (1996). This chemical compound induced micronuclei whether the enzyme was present or not when Doherty and co-workers treated lymphoblastoid cell lines with 1,2-dichloroethane and the micronuclei induced were kinetochore negative. The differences between the results from two different assays are difficult to explain since the dose range used was identical in both assays, however some possible suggestions are that the lymphoblastoid cell lines may have been more sensitive to this particular chemical compound than the Chinese hamster cell lines, or the induction of micronuclei in the nonmetabolically competent lymphoblastoid cells may have derived mainly from the damage in the centromere 
1,1,2-trichloroethane (V79d-MZ)

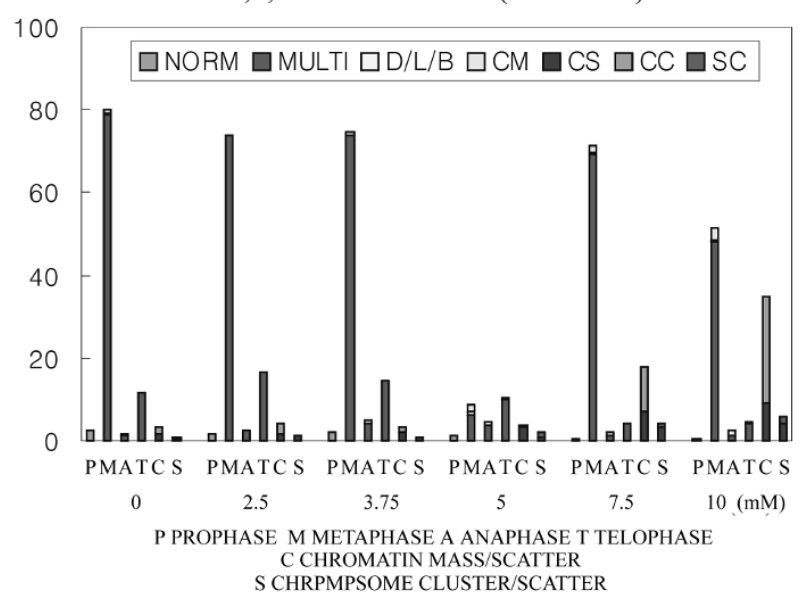

1,1,2-trichloroethane (MB1)

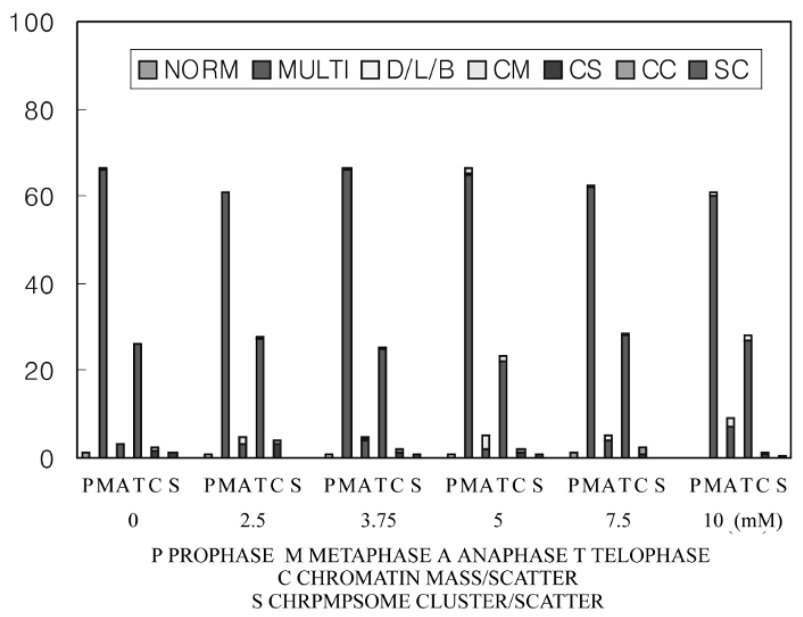

Figure 2. Mitotic profiles of $\mathrm{V} 79 \mathrm{~d}-\mathrm{MZ}(\mathrm{A})$ and $\mathrm{MB} 1(\mathrm{~B})$ treated with 1,1,2trichloroethane. A large number of aberrations were present at the highest dose used in V79d-MZ and more aberrant cells than normal cells were present at the dose of $10 \mathrm{mM}$ in MB1.

rather than the spindle damage and this idea is consistent with the induction of kinetochore negative micronuclei in Doherty's work.

A large number of $D / L / B$ was scored in MB1 cell line and a possible mechanism inducing D/L/B can be explained by a demonstration of Yoo and Vig, 1993, that the chromosomes lacking kinetochore proteins $\left(\mathrm{K}^{-}\right)$were unable to attach on to the spindle apparatus.

Crebelli and co-workers in 1988 have shown that 1,2dichloroethane induced chromosomal malsegregation in A. nidulans without any enzyme activity as Doherty's work has shown but this was not consistent with the spindle assay result and this difference may have been due to different types of cell lines used and the sensitivity of different assays may have been another factor to consider in explaining the difference in the results.

\section{1,1,2-trichloroethane}

This chemical compound was found to be a spindle poison in both cell lines. In the V79d-MZ, there were no significant changes in the mitotic profiles until a dose of $7.5 \mathrm{mM}$ was reached, and at a dose of $10 \mathrm{mM}$ the frequency of metaphase decreased and the number of spindle-absent cells increased approximately by twofold (Figure 2A). In the MB1, between the dose range of 2.5 to $7.5 \mathrm{mM}$, many dislocated chromosomes were induced by the chemical but did not show any dosedependent manner (Figure 2B). At a dose of $10 \mathrm{mM}$ the metaphase frequency dropped by more than two-fold.

1,1,2-trichloroethane was a spindle poison with or without the CYP2E1 activation however the chemical was more toxic when the enzyme metabolised the chemical compound. An isomer of this chemical compound, 1,1,1-trichloroethane seems to be a weaker spindle poison (Adele Kim, Ph.D Thesis 1998) than 1,1,2trichloroethane since for both chemical compounds the identical dose range induced different levels of aberration. In fact, one isomer was more effective than the other for inducing aberrant cells. This shows that the chemical structure is important when the toxicity of a chemical compound is considered.

\section{Trichloroethylene}

The V79d-MZ treated with trichloroethylene did not show many changes in their mitotic profiles compared to its negative control although the doses were raised up to $10 \mathrm{mM}$ (Figure 3A). However metabolically competent cell lines, MB1 has shown a variety of aberrations in their mitotic profiles (Figure 3B). The MB1 cells were not scorable at a dose of $10 \mathrm{mM}$, and at lower doses large numbers of $\mathrm{D} / \mathrm{L} / \mathrm{B}$ and multi-polar cells were induced in a dose-dependent manner.

Trichloroethylene required the CYP2E1 activation in order to induce some spindle damage or some other forms of aberrations such as D/L/B. The induction of D/ L/B may have been derived via several pathways, for instance an inhibition of a motor protein such as dynein may be one way, presence of antibodies for centromere weakens the association of dynein with the kinetochore and this may eventually lead to chromosomes failing to move normally. Chloral hydrate is one of the metabolites of trichloroethylene and chloral hydrate is known to stop elongation of microtubules (Ris, 1949) and the disruption of normal movement of the chromosomes along the spindle apparatus may have been due to metabolites such as chloral hydrate.

Miller and Guengerich (1982) proposed a mechanism leading to chloral hydrate formation. According to their model, chlorine migration occurs within an oxygenated TCE-cytochrome P-450 transition state without the involvement of an epoxide as an intermediate. Chloral hydrate is then reduced to trichloroethanol and oxidized to trichloroacetic acid (Kawamoto et al., 1987). The latter of the two metabolites seems to be responsible for 
Trichloroethylene (V79d-MZ)

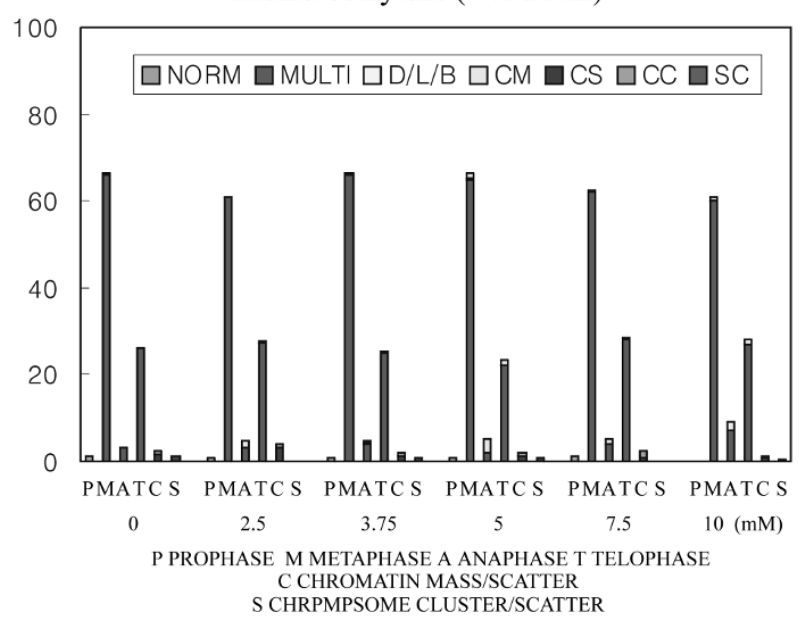

Trichloroethylene (MB1)

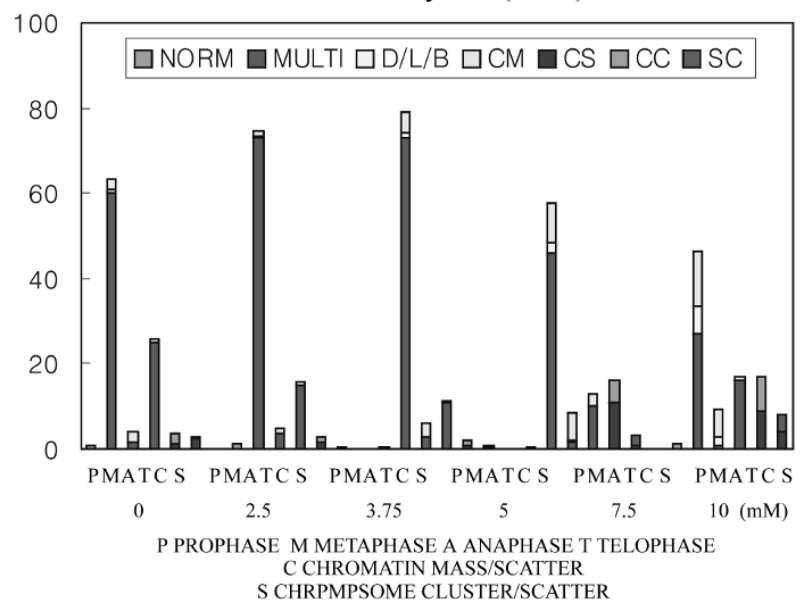

Figure 3. Mitotic profiles of $\mathrm{V} 79 \mathrm{~d}-\mathrm{MZ}(\mathrm{A})$ and $\mathrm{MB} 1(\mathrm{~B})$ treated with trichloroethylene. Cells were treated with the chemical compound for 1.33 cell cycle time and differentially stained. Most cells were kept as normal cells in V79d$\mathrm{MZ}$ but there were no cells to score at the dose of $10 \mathrm{mM}$ in MB1.

the hepatocarcinogenic action of TCE via peroxisomal proliferation (Elcombe, 1985).

\section{2,3-dichlorobutane}

The Figure 4A shows the mitotic profiles of V79d-MZ treated with 2,3-dichlorobutane between a dose range of 0 to $5 \mathrm{mM}$ and as the doses were increased the number of spindle-absent cells increased. Many numbers of $\mathrm{D} / \mathrm{L} / \mathrm{B}$ and multi-polar spindles were also induced when the V79d-MZ cells were treated with this chemical compound.

The Figure 4B shows the mitotic profiles of MB1 treated with 2,3-dichlorobutane using the same dose range used for V79d-MZ. The number of spindle-absent cells increased in a dose-dependent manner as the frequency of metaphase decreased and the numbers of multipolar spindles and D/L/B also increased in a dose-
2,3-Dichlorobutane (V79d-MZ)

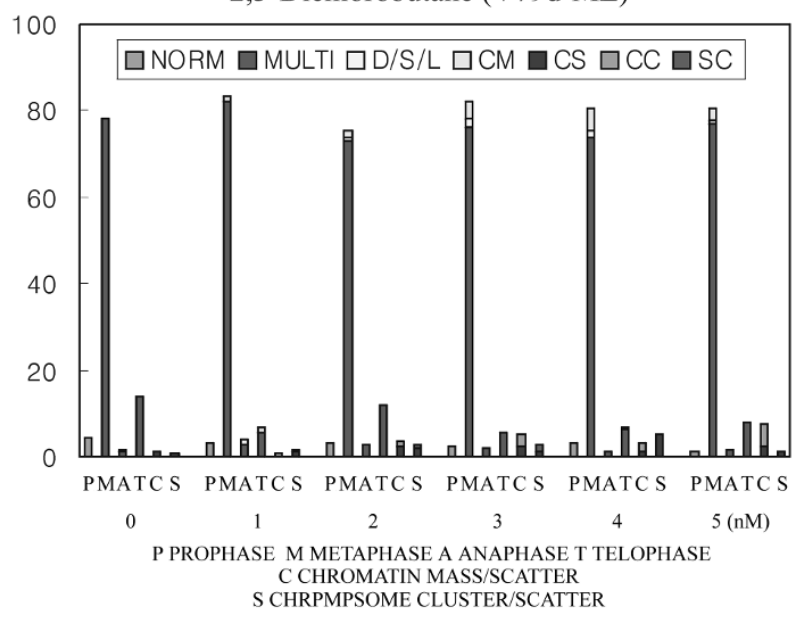

2,3-Dichlorobutane (MB1)

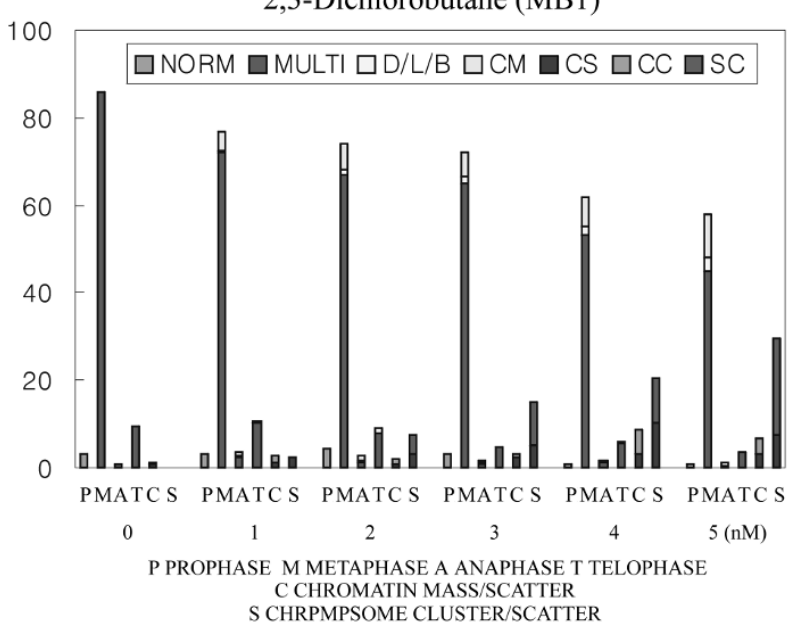

Figure 4. Mitotic profiles of $\mathrm{V} 79 \mathrm{~d}-\mathrm{MZ}(\mathrm{A})$ and $\mathrm{MB1}(\mathrm{B})$ treated with 2,3dichlorobutane. First graph suggests that 2,3-dichlorobutane requires P450 activation to be spindle poisonous since not many aberrant cells were found in V79d-MZ. However, the latter graph clearly shows bioactivation of CYP2E1 since many aberrant cells were induced.

dependent manner.

2,3-dichlorobutane required an enzyme activation to be a spindle poison and the induction of micronuclei with kinetochore labels (Doherty et al., 1996) indicates that the chemical compound is more of an aneugen than a clastogen however this does not necessarily mean that the kinetochores were functioning efficiently, unless molecular assays are carried out to analyse the sequence of the centromere.

Some multi-polar spindles were induced not only for this particular compound but for many of the chemical compounds tested in this study, and the induction of these multipolar spindles can be achieved by several ways, for instance replication of more than two centrosomes in one cell cycle will eventually produce multipolar spindles. In 1996, it was discovered that the 

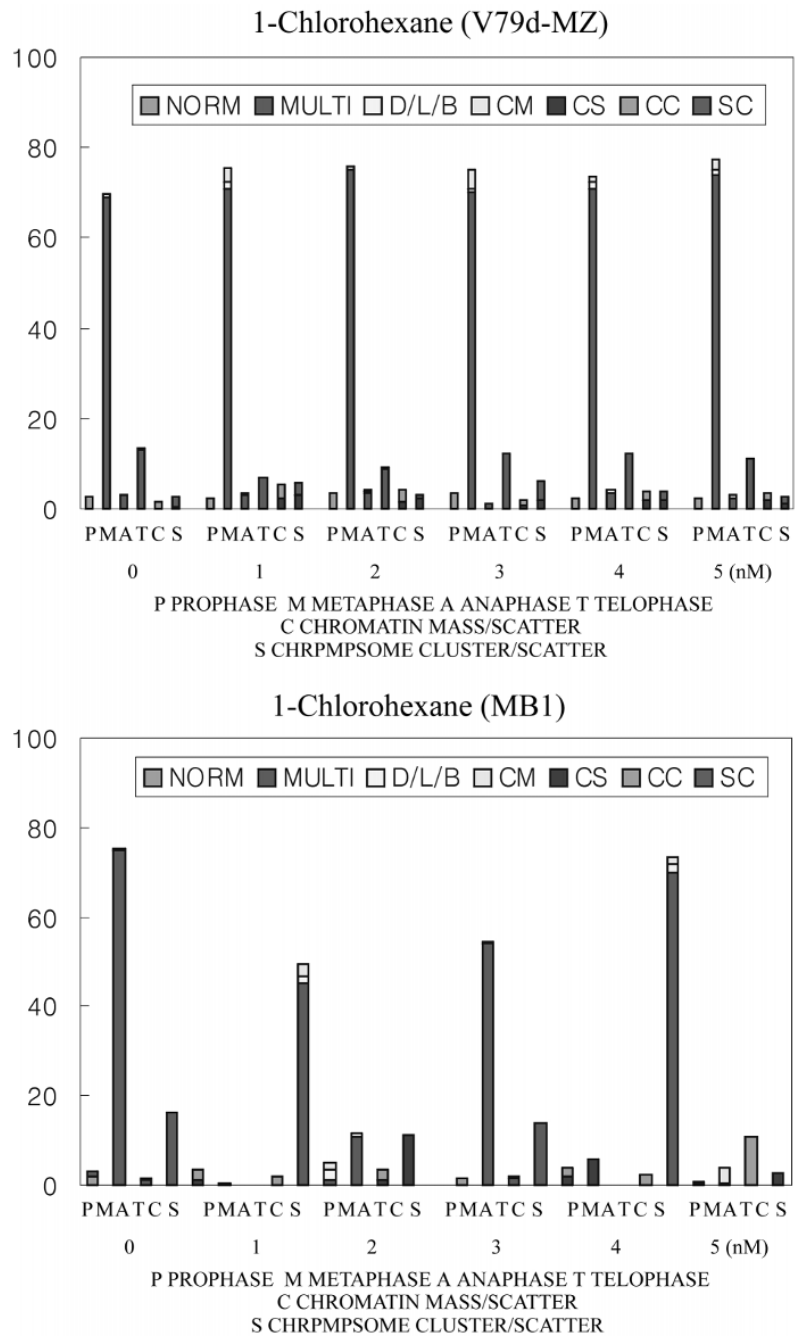

Figure 5. Mitotic profiles of $\mathrm{V} 79 \mathrm{~d}-\mathrm{MZ}(\mathrm{A})$ and $\mathrm{MB1}(\mathrm{B})$ treated with 1chlorohexane. The dose range used for 1-chlorohexane is between 0 to 2.5 $\mathrm{mM}$, much less than the rest of the chemical compounds tested but high toxicity is shown. All the MB1 cells were dead for the last two doses and this represents that the CYP2E1 enzyme made the chemical to be more cytotoxic.

absence of p53 proteins in mouse embryonic fibroblasts produced more than two centrosomes in a cell cycle and this eventually led to multi-polar cells (Fukasawa et al., 1996).

It was thought until recently that centrosomes are essential for cells to be bipolar however Wilson and coworkers have discovered that in urchin and Drosophila, the bipolar cells were present in monastral state where no $\gamma$-tubulins were found (Wilson et al., 1997). This postulates that multi-polar spindle formation induced by these chemicals may not be necessarily due to absent or amplification of centrosomes but it may be due to other defects in organelles, genes or proteins.

\section{1-chlorohexane}

The mitotic profiles of V79d-MZ treated with 1-chloro- hexane show no significant changes compared to its negative control (Figure 5A) except for that there is a large number of $D / L / B$ when the cells were treated with this chemical - compound between a dose range of 0.5 to $2.5 \mathrm{mM}$, however this was not in a dose-dependent manner.

The mitotic profiles of MB1 shows that none of the cells were scorable or observed at a dose of $2 \mathrm{mM}$ (Figure 5B) and at a lower dose, many cells were spindle-absent.

1-chlorohexane is a chemical which has not much other toxicological information other than Doherty's work and this makes it difficult to discuss the result however this chemical compound was toxic and induced severe spindle damage when the enzyme was present which eventually led to cell death at a low dose.

It has been known for a while that dysfunctional centrosome can also induce spindle-absent cells. Boleti and co-workers found out that there is a centrosomal kinesin-like protein which is required for centrosome separation during mitosis in Xenopus (Boleti et al.,1996) and if this protein is inhibited somehow, the centrosome may not separate and then this may induce spindleabsent cells. Once it was suggested that centrioles were also essential for the cell division however some cells were found to be dividing without centrioles (Calarco et al.,1972). It seems therefore difficult to know for certain what are the essential components required for normal cell division. It seems to vary depending on the origin of cells.

The complete formation of microtubules is also dependent upon whether or not chromosomes are present on the spindle (Zhang and Nicklas, 1995) and this shows an indirect way of affecting the polymerisation of microtubules. The evidence of this kind allows us to postulate that clastogenicity influences aneugenicity thus chromosomal damage may also be influencing the integrity of spindles.

The absence of a mitotic spindle can be induced not only at the cellular level but also at the molecular level, for example a null mutation in the gamma-tubulin gene causes a complete loss of the mitotic spindle in $A$. nidulans (Stearns et al., 1991).

All five chemical compounds used induced not only spindle damage but damaged genetic material (DNA) and this is confirmed for some of the chemicals investigated here by Tafazoli and Kirsch-Volders in 1996 when they carried out the comet assays.

To summarise from both our own study and that of others discussed, it is concluded that four of the chemical compounds were found to be direct spindle poisons and only one chemical showed elevated levels of aberrations when the enzyme CYP2E1 was expressed, and this indicates that the enzyme was more of a toxifying enzyme than detoxifying one.

There are many possible factors as already discuss- 
ed, which are involved either directly or indirectly in inducing spindle damage, however the spindle assay method used in this study only allows us to postulate some possible mechanisms of inducing spindle or chromosomal damage only, nevertheless this study seems to have opened up many further possibilities to study the mechanisms of aneugenicity and clastogenicity.

\section{References}

Boleti H, Karsenti E, Vernos I. Xklp2, a novel Xenopus centrosomal kinesin-like protein required for centrosome separation during mitosis. Cell 1996;84:49-59

Calarco PG, Donahue RP, Szöllösi, D. Germinal vesicle breakdown in the mouse oocyte. J Cell Sci 1972;10:369-85

Crebelli R, Benigni R, Franekic J, Conti G, Conti L, Carere A. Induction of chromosome malsegregation by halogenated organic solvents in Aspergillus nidulans: unspecific or specific mechanism? Mut Res 1988;201:401-11

Doherty AT, Ellard S, Parry EM, Parry JM. An investigation into the activation and deactivation of chlorinated hydrocarbons to genotoxins in metabolically competent human cells. Mutagenesis 1996;11:247-74

Elcombe CR. Species differences in carcinogenicity and peroxisome proliferation due to trichloroethylene: a biochemical human hazard assessment. In: Receptors and other targets for toxic substances. Arch Toxicol Suppl 1985;8:6-17

Eurocop-Cost. A comprehensive list of polluting substances which have been identified in various fresh waters, effluent discharges, aquatic animals and plants and bottom sediments 2nd ed. Vol. EUCO/MDU/73/76, XII/476/76, Luxembourg, Comission of the European Communities.1976;29

Fujii T. Direct aqueous injection gas chromatography-mass spectrometry for analysis of organohalides in water at concentrations below the parts per billion level. J Chromatography 1977;139:297-302

Fukasawa K, Choi T, Kuriyama R, Rulong S, Vande Woude GF. Abnormal centrosome amplification in the absence of p53. Science 1996;271:1744-1

Kawamoto T, Hobara T, Kobayashi H, Iwamoto S, Sakai T, Ogino K. Alteration of chloral hydrate metabolism in rats with carbon tetrachloride-induced liver-damage. Toxicol. Letters 1987;37:263-68

Kim A. Ph.D Thesis. The effect of twelve chlorinated aliphatic hydrocarbons upon the cell cycle of Chinese hamster cell lines: V79d-MZ and genetically engineered cell lines expressing
CYP2E1. 1998

Koop DR, Tierney DJ. Multiple mechanisms in the regulation of ethanol-inducible cytochrome-P450IIE1. BioEssays 1990; 12:429-35

Lieber CS. Biochemical and molecular-basis of alcoholinduced injury to liver and other tissues. New Eng $\mathrm{J}$ Med 1988;319:1639-50

Miller RE, Guengerich FP. Oxidation of trichloroethylene by liver microsomal cytochrome P-450: evidence for chlorine migration in a transition state not involving trichloroethylene oxide. Biochem 1982;21:1090-97

Parry EM, Danford N, Parry JM. Differential staining of chromosome and spindle and its use as an assay for determining the effect of diethylstilboestrol on cultured mammalian cells. Mut Res 1982;105:243-52

Ris $\mathrm{H}$. The anaphase movement of chromosomes in the spermatocytes of the grasshopper. Biological Bulletin 1949; 96:90-106

Ronis MJJ, Huang JA, Crouch J, Mercado C, Irby D, Valentine CR, Lumpkin CK, Ingelmansundberg M, Badger TM. Cytochrome-P-450 CYP2E1 induction during chronic alcohol exposure occurs by a 2-step mechanism associated with bloodalcohol concentrations in rats. J Pharmaco Exp Thera. 1993; 264:944-50

Steams T, Evans L, Kirschner M. Gamma tubulin is a highly conserved component of the centrosome. Cell 1991;65:82536

Szende B, Tyihak E, Kiraly-Veghely Z. Dose dependent effect of resveratrol on proliferation and apoptosis in endothelial and tumor cell cultures. Exp Mol Med 2000;32:88-92

Wilson PG, Fuller MT, Borisy GG. Monastral bipolar spindles: implications for dynamic centrosome organization. J Cell Sci 1997; 110:451-64

Wissinger WL, Estervig DN, Wang RJ. A differential staining technique for simultaneous visualization of mitotic spindle and chromosomes in mammalian cells. Stain Technology 1981; 56:221-26

Yoo HJ, Vig BK. Chromosomes lacking kinetochore proteinstheir meta-anaphase location suggests potential malsegregation. Mutagenesis 1993;8:553-60

Yoo J-SH, Guengerich FP, Yang CS. Metabolism of N-nitrosodialkylamines by human liver microsomes. Cancer Res 1988;88:1499-15

Zhang DH, Nicklas RB. The impact of chromosomes and centrosomes on spindle assembly as observed in living cells. J Cell Biol 1995;129:1287-30 